\title{
PROTOCOL FOR ASSESSING THE PRECISION OF PARALYMPIC BOCCIA PLAYERS
}

\author{
PROTOCOLO PARA AVALIAÇÃO DA PRECISÃO DE JOGADORES DE BOCHA PARALÍMPICA
}

Original Article

ARTIGO ORIGINAL Artículo Original

\author{
PROTOCOLO PARA EVALUAR LA PRECISIÓN DE LOS JUGADORES DE BOCHAS PARALIMMPICA
}

\begin{abstract}
José Igor Vasconcelos de Oliveira' (Physical Education Professional)

Lúcia Inês Guedes Leite de Oliveira² (ID) (Physical Education Professional) Manoel da Cunha Costa ${ }^{3}$ (D) (Physical Education Professional) Sidcley Félix de Arruda' (DD (Physical Education Professional) Saulo Fernandes Melo de Oliveira ${ }^{4}$ (ID) (Physical Education Professional)
\end{abstract}

1. Universidade Federal de Pernambuco, Postgraduate Program in Physical Education, PE, Brazil.

2. Universidade de Pernambuco, Universidade Federal da Paraíba, Associated Postgraduate Program in Physical Education, Human Performance Assessment Laboratory, Brazilian Paralympic Academy, Recife, PE, Brazil. 3. Universidade de Pernambuco, Escola Superior de Educação Física, Human Performance Assessment Laboratory, Recife, PE, Brazil. 4. Universidade Federal de Pernambuco, Centro Acadêmico de Vitória, Physical Education and Sports Sciences Center, Brazilian Paralympic Academy, Recife, PE, Brazil.

\section{Correspondence}

Saulo Fernandes Melo de Oliveira. Rua Alto do Reservatório, sem número, Bela Vista, Vitória de Santo Antão, PE, Brasil.

saulofmoliveira@gmail.com

\section{ABSTRACT}

Introduction: Although Paralympic boccia is an up-and-coming sport, demanding more and requiring higher levels of performance from athletes, protocols are not available for evaluating its indicators. Objective: To develop and verify the applicability of a new protocol for assessing the precision of athletes of the sport. Methods: Two targets with two different resolutions (0.5 [RES-0.5] and 1.0 [RES-1.0] points) were developed, graduated from 1 to 7 . The protocol consists of placing the targets at 6 locations on the court, and each athlete makes two shots for each target. The best results are considered, from which total precision (TotalP), short precision (SP), medium precision (MP) and long precision (LP) are extracted. Nine players participated in the application of the protocol. The indicators of both targets were compared and verified using the intraclass correlation coefficient (ICC), standard error of measurement (SEm), bias (Bland-Altman) and minimum detectable difference (MDD). Results: Only for LP were there differences between targets (RES-0.5: 9.111 versus RES-1.0: 7.167; $p<0.05$ ), while TotalP, SP and MP did not show any significant differences (RES-0.5: 23.11 versus RES-1.0: 25.39; RES-0.5: 18.22 versus RES-1.0: 17.78; RES-0.5: 9.11 versus RES-1.0: 12.44, respectively). In addition, the RES-0.5 target obtained better concordance results (ICC $=0.73$; SEm $=3.45$; bias $=-0.5938 ; \mathrm{MDD}=8.00$ ), while the RES-1.0 target obtained lower values $(\mathrm{CCl}=0.53 ; \mathrm{SEm}=6.28 ;$ bias $=0.3750 ; \mathrm{MDD}=14.56)$. Conclusion: The proposed protocol presents excellent applicability results. However, a larger sample of athletes including more details on specific precision indicators should be performed. Level of evidence Il; Prospective comparative study.

Keywords: Disabled persons; Physical education and training; Athletic performance; Sports medicine.

\section{RESUMO}

Introdução: Embora a bocha paralímpica seja uma modalidade em ascensão, requerendo maiores níveis de exigência e desempenho dos atletas, não estão disponíveis protocolos para avaliação de seus indicadores. Objetivo: Desenvolver everificar a aplicabilidade de um novo protocolo para avaliação da precisão de atletas da modalidade. Métodos: Dois alvos com duas resoluções distintas (0,5 [RES-0,5] e 1,0 [RES-1,0] pontos) foram desenvolvidos, com graduação de 1 a 7 . O protocolo consiste na colocação dos alvos em 6 pontos na quadra, e cada atleta executa dois lançamentos para cada ponto. São considerados os melhores resultados, onde se extraem a precisão total (Ptotal), a precisão curta (PC), precisão média (PM) e a precisão longa (PL). A partir daí 9 jogadores participaram da aplicação. Os indicadores de ambos alvos foram comparados e verificados por meio do coeficiente de correlação intraclasse (CCI), erro padrão de medida (EPM), viés (Bland-Altman) e mínima diferença detectável (MDD). Resultados: Apenas para a PL houve diferenças entre os alvos (RES-0,5:9,111 contra RES-1,0: 7,167; $P<0,05$ ), enquanto que a Ptotal, PC e PM não apresentaram diferenças significativas (RES-0,5:23,11 contra RES-1,0:25,39; RES-0,5: 18,22 contra RES-1,0: 17,78; RES-0,5: 9, 11 contra RES-1,0:12,44, respectivamente). Na concordância, o alvo RES-0,5 obteve melhores resultados de concordância (CCI=0,73; $E P M=3,45 ;$ viés $=-0,5938 ; M D D=8,00)$, enquanto o alvo $R E S-1,0$ obteve valores inferiores (CCl=0,53; $E P M=6,28 ;$ viés=0,3750; $M D D=14,56$ ). Conclusão: $O$ protocolo proposto apresenta resultados excelentes de aplicabilidade. Contudo, uma amostra maior de atletas incluindo mais detalhes sobre os indicadores especificos de precisão devem ser realizados. Nível de evidência ll; Estudo prospectivo comparativo.

Descritores: Pessoas com deficiência; Treinamento físico; Desempenho atlético; Medicina do esporte.

\section{RESUMEN}

Introducción: Aunque la boquia paralímpica es una modalidad prometedora, que requiere mayores niveles de demanda y rendimiento de los atletas, los protocolos para la evaluación de sus indicadores no están disponibles. Objetivo: Desarrollary verificar la aplicabilidad de un nuevo protocolo para evaluar la precisión de los atletas. Métodos: Se desarrollaron dos objetivos con dos resoluciones diferentes (0.5 [RES-0.5] y 1.0 [RES-1.0] puntos), calificando de 1 a 7. El protocolo consiste en colocar los objetivos en 6 puntos en la cancha, y cada atleta ejecuta dos disparos por cada punto. Se consideran los mejores resultados, donde se extraen precisión total (Ptotal), precisión corta (PC), precisión media (PM) y precisión larga (PL). Asi, 9jugadores participaron en la aplicación. Los indicadores de ambos objetivos se compararon y verificaron utilizando el coeficiente de correlación intraclase (CCI), el error estándar de medición (EEM), 
el sesgo (Bland-Altman) y la diferencia mínima detectable (MDD). Resultados: Solo para PL hubo diferencias entre los objetivos (RES-0.5: 9.111 frente a RES-1.0: 7.167; P<0.05), mientras que Ptotal, PC y PM no mostraron diferencias significativas (RES-0.5: 23.11 contra RES-1.0: 25.39; RES- 0.5: 18.22 contra RES-1.0: 17.78; RES-0.5: 9.11 contra RES- 1.0: 12.44, respectivamente). De acuerdo, el objetivo RES-0.5 obtuvo mejores resultados de acuerdo (CCI $=0.73 ; E E M=$ 3.45; sesgo = -0.5938; $\mathrm{MDD}=8.00)$, mientras que el objetivo RES-1.0 obtuvo valores más bajos $(C C l=0.53 ; E E M=6.28$; sesgo $=0.3750 ; M D D=14.56)$. Conclusión: El protocolo propuesto presenta excelentes resultados de aplicabilidad. Sin embargo, se debe realizar una muestra más grande de atletas que incluya más detalles sobre indicadores de precisión específicos. Nivel de evidencia Il; Estudio prospectivo comparativo.

Descriptores: Personas con discapacidad; Entrenamiento físico; Rendimiento atlético; Medicina Deportiva.

\section{INTRODUCTION}

Paralympic boccia is a sport that has been present on the Paralympic scene since the 1984 edition of the games (New York). ${ }^{1}$ It is a sport especially dedicated to and adapted for people with severe motor disabilities, among them cerebral palsy, quadriplegia, degenerative diseases and malformations. ${ }^{2}$ It consists of four functional classes, two of which are dedicated exclusively to cerebral palsy (BC1 and BC2) and two others that are open to other types of disability. ${ }^{1,2}$ Regarding its practice, the number of countries participating in the most recent world events has grown, a fact that has also fostered increased athlete performance.

This mixed-sex sport can be played individually, by pairs, or by teams (of three), with men and women on the same team or even competing against each other. Despite the athlete's functional class, Paralympic boccia is characterized as a sport in which technique and technique are causally related to precision. The players alternate in consecutive throws to approach the determined target, which can be the target ball (white) or another ball that is on the playing field.

Thus, the training and preparation routines of the athletes should mostly be related to producing strategies that favor an increase in motor control, generating greater consistency in the successive tactical demands for maintaining their throwing precision. ${ }^{3}$ Although studies with controlled and randomized interventions in the modality are scarce, it has been shown that training techniques linked to systematization ${ }^{4}$ of the sessions and the aid of virtual technologies ${ }^{5}$ can be used effectively and safely for the athletes.

Although the importance of gaining greater motor control and dedicating a large part of training to developing the athlete's precision in real game situations is recognized, the proposals developed to date to assess precision indicators are not yet standardized ${ }^{6,7}$ and are usually related to approximation techniques dependent on the analysis scenario provided or even on observation of hits and misses in follow-up studies.

It should be noted that other Paralympic sports, such as wheelchair basketball, ${ }^{8}$ rugby, ${ }^{9}$ tennis ${ }^{10}$ and volleyball, ${ }^{11}$ have shown good results by proposing protocols and batteries of specific tests. However, methodologies and protocols to evaluate precision indicators for Paralympic boccia have not yet been planned, developed or tested, with the exception of procedures for the functional evaluation of athletes. ${ }^{12,13}$ Such performance-related information is valuable for trainers and athletes to obtain data related to progress during specific periods of the competitive year.

Thus, in view of the gap present in the context of sports preparation for Paralympic boccia athletes, our objectives are: a) to demonstrate the development of a protocol for assessing precision in Paralympic boccia and $b$ ) to present the applicability of the protocol in experienced players, comparing the results of the versions of the protocol created and verifying the stability of the test-retest measurements in the sample of athletes.

\section{METHODS}

\section{Study, subjects and ethical considerations}

All procedures in this study adhered to ethical standards for research with human beings (opinion no. 3.719.663) and the Informed Consent Form was obtained from each participant. All participants had experience playing Paralympic boccia in regional, national and international events. The sample consisted of 9 individuals ( 6 males and 3 females).

\section{Equipment development}

Two targets were designed, each with a maximum diameter of 100.5 centimeters, graduated from 1 to 7 points, with the values increasing from the edges of the target to the center of the circle. What differed between the two circular targets was the width of the scoring zones and also the sensitivity of the graduation. In both targets the scoring ranged from 1 to 7 , with 0.5 points of resolution in one of the targets (RES-0.5) while the other enables a resolution of 1.0 point (RES-1.0). Both can be used in the same way within the proposed protocol. The maximum total score permitted is 42.0 points for both targets.

\section{Protocol organization}

Three distances were determined on the court, at 3,6 and 9 meters from the limit line of the boxes. The center points of the upper lines of boxes 2 and 5 were used as parameters. Each player had to position themselves in boxes 3 and 4 (in that order) and direct their throws laterally to the right if they were in box 4 and to the left if they were in box 3. Each player threw two balls from each position (right and left), and the better throw (higher score) from each position was considered.

Before each throw, in each position on the court, the player positioned themselves in their chair in the direction of the throw, without the time required for each attempt being counted. Before the throws, there was a two-minute warm-up period with the balls chosen by the player. Each player had 30 seconds to make the throw from the determined position. The 30-second time was defined for all the functional classes, considering the entire preparatory phase for the throws. The player could make two throws from each position on the court and the better one was considered. If the player achieved the maximum score on the first throw from a position, the second attempt was not made. The throws were conducted in increasing order of the positioning of the targets on the court.

The number corresponding to the perimeter was noted for the record. If the athlete was unable to reach the first perimeter of the target (position 1) in either of the two throws, a value of 0.5 was assigned for that throw. In situations where the ball came to a stop between two perimeters, the perimeter with the larger portion (hemisphere) of the ball was considered. If it was not possible to establish a larger portion between the two perimeters, the intermediate value between the two perimeters was assigned. (Figure 1) 


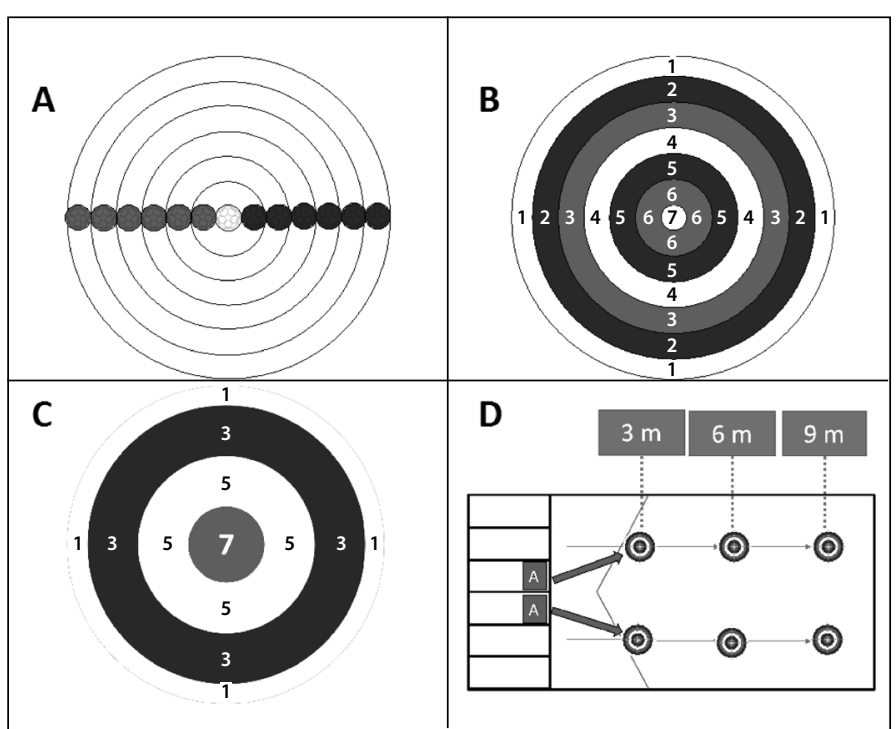

Figure 1. Targets designed, with their dimensions, for the evaluation of the boccia player's throw. Panel A (scale of the target size, Panel B (target with 1.0-point resolution), Panel C (target with 0.5-point resolution), Panel D (organization of the court for application of the protocol).

\section{Determination of the precision indicators}

The sum of the best results achieved by the athletes for each throwing distance $(3,6$ and 9 meters) will be considered the "maximum precision", being possible for each athlete to score 42 points ( 7 points $\times 6$ attempts). After determining the final precision value (total precision), the consistency of each throw was verified according to the sum of points achieved in the four regions of the court. Thus, short, medium and long precision were calculated from the sum of the four throws made, being possible to achieve up to 28 points for each consistency indicator. Consistency indicators are useful in verifying in which regions of the field the athletes would have greater mastery of the technique and greater possibility of hits. Based on this information, we propose classifying the athletes' precision using the cutoff points shown in Chart 1.

\section{Evaluation of applicability}

Two applicability procedures were conducted. In the first, nine athletes were recruited to participate in the applicability experiments. The differences between the measurements obtained for the two projected targets were verified by comparing the mean values of each variable analyzed. In the second, a subsample containing the athletes was evaluated on two non-consecutive days, 7 days apart. This smaller subsample included only those athletes who were effectively evaluated within the time interval necessary to test the stability of the measurements. This procedure was conducted taking the nature of the variable analyzed (precision) and the influencing factors, such

Chart 1. Cutoff point for the classification of precision indicators.

\begin{tabular}{|c|c|}
\hline \multicolumn{2}{|c|}{ Classification of maximum precision } \\
\hline Final score achieved & Suggested classification \\
\hline$<10.5$ & Low precision \\
\hline 11.0 to 21.5 & Fair precision \\
\hline 22 to 32.0 & Good precision \\
\hline$>32.0$ & Excellent precision \\
\hline Precision consistency classification & short, medium and long distances) \\
\hline$<7.0$ points & Low precision \\
\hline 7 to 13.9 points & Food precision \\
\hline 14 to 20.9 points & Excellent precision \\
\hline$>21$ points
\end{tabular}

as fatigue, into account. ${ }^{14}$ The tests were administered at the location where the athletes train, at the same time of day, on a level sports court with a cement floor. In all situations, the order of application of the targets and all procedures were followed in a standardized manner, performed by the same team of evaluators.

\section{Statistical analysis}

The normality of the data was confirmed using the Shapiro-Wilk test. The paired sample t-test was performed to compare the mean values obtained for the two developed targets. To verify the stability of the measurements the values obtained on day 1 and day 2 were compared using the Wilcoxon test. To check the concordance between the two days of application we opted to use the Bland Altman graphical analysis method, ${ }^{15}$ combining the precision indicators (short, medium, long) into a single group with verification of the respective biases and established limits of agreement (inferior and superior). This unification procedure was necessary due to the reduced number of subjects for this phase of the applicability. In addition, the intraclass correlation coefficient (ICC) and the standard error of measurement (SEm), using the equation $S E m=S D \times \sqrt{1-I C C}$, where SD is the greatest standard deviation verified between the data collection moments ( 1 and 2), were calculated. With these indicators, the minimum detectable difference (MDD) was calculated using the formula $M D D=1.64 \times \sqrt{2 \times S E m}$. Such strategies have been used in previous studies. ${ }^{16}$ The data were analyzed using Prism, version 6.0 software (Graphpad, USA) and the level of significance adopted was $5 \%(p<0.05)$.

\section{RESULTS}

Table 1 contains the descriptive data of all volunteers who participated in the data collection phases of the study.

The comparison between the precision indicators obtained for both projected targets is shown in Figure 2. Significant differences are observed only for "long precision" (target 0.5=9.111 points, target 1.0=7.167 points; $\mathrm{p}<0.05)$. No significant differences were found for "total precision" (target $0.5=23.11$ points, target $1.0=25.39$ points; $\mathrm{p}<0.05)$, "short precision" (target $0.5=18.22$ points, target $1.0=17.78$ points; $\mathrm{p}<0.05$ ) or "medium precision" (target $0.5=9.11$ points, target $1.0=12.44$ points; $p<0.05$ ). Moreover, we observed that, for all indicators evaluated, the classifications did not change in accordance with the cutoff points suggested in Chart 1.

The data for concordance between the collection days (1 and 2), verified by the Bland-Altman method, are presented in Figure 3. Weak and insignificant biases are observed for each of the targets applied and are considered acceptable (target 1.0: $p=0.6477$; target 0.5: $p=0.8596$ ), and most of the difference values fall within the established limits of agreement $(95 \% \mathrm{Cl})$.

Table 1. Descriptive data of the players participating in the study.

\begin{tabular}{c|c|c|c|c|c}
\hline ID & $\begin{array}{c}\text { Age } \\
\text { (years) }\end{array}$ & $\begin{array}{c}\text { FC } \\
\text { (points) }\end{array}$ & $\begin{array}{c}\text { Disability } \\
\text { (type) }\end{array}$ & $\begin{array}{c}\text { Length of experience } \\
\text { (months) }\end{array}$ & $\begin{array}{c}\text { Weekly training } \\
\text { volume (hours) }\end{array}$ \\
\hline 01 & 29 & BC2 & CP & 48 & 24 \\
\hline 02 & 36 & BC2 & CP & 48 & 18 \\
\hline 03 & 24 & BC4 & CMF & 24 & 12 \\
\hline 04 & 24 & BC3 & MD & 3 & 12 \\
\hline 05 & 18 & BC1 & CP & 48 & 12 \\
\hline 06 & 23 & BC2 & CP & 96 & 12 \\
\hline 07 & 31 & BC4 & MD & 48 & 12 \\
\hline 08 & 36 & BC2 & CP & 84 & 12 \\
\hline 09 & 24 & BC1 & CP & 72 & 12 \\
\hline M & 26.0 & -- & -- & 49.50 & 13.40 \\
\hline SD & 6.06 & -- & -- & 28.54 & 4.43 \\
\hline
\end{tabular}

Key: ID (player identification number), FC (functional class, M (mean), SD (standard deviation), CP (cerebral palsy), CMF (congenital malformation), MD (muscular dystrophy). 
The reproducibility indicators are displayed in Table 2. Excellent and moderate ICC values were observed in our analysis of days 1 and 2 for the 0.5 resolution and 1.0 resolution targets, respectively. Lower SEm and MDD values were observed for 0.5 resolution target. Only the bias value observed was higher for the 1.0 resolution target.

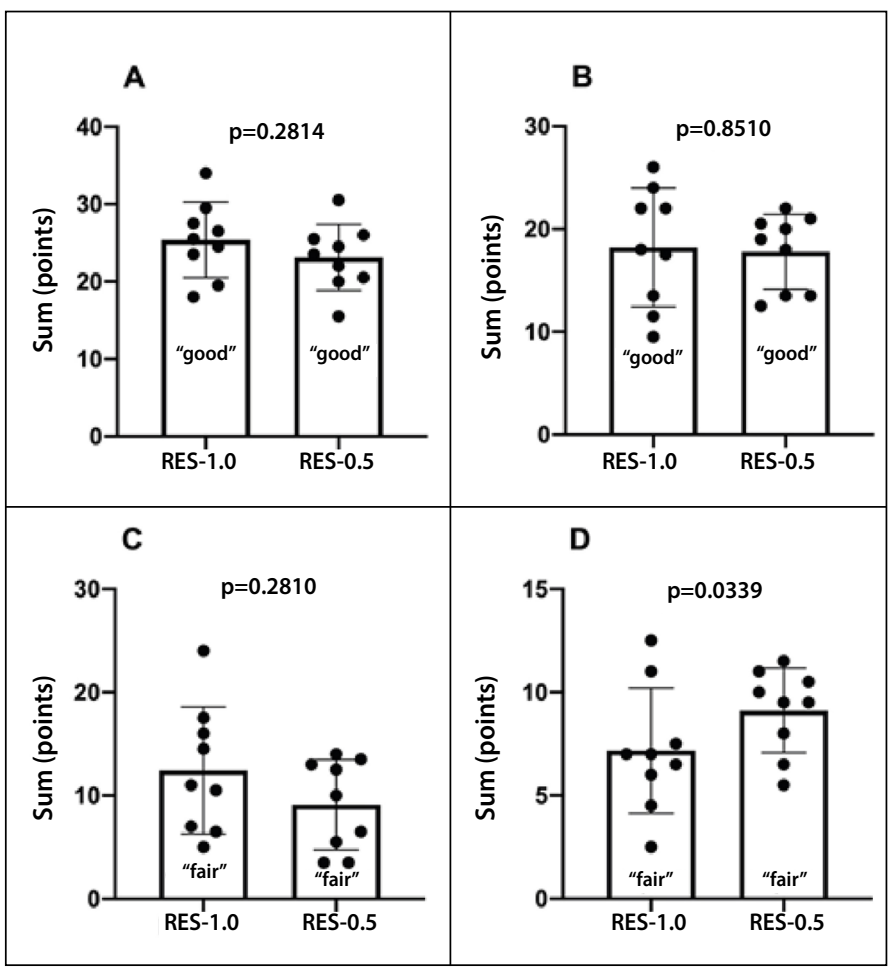

Figure 2. Comparisons between the developed targets.

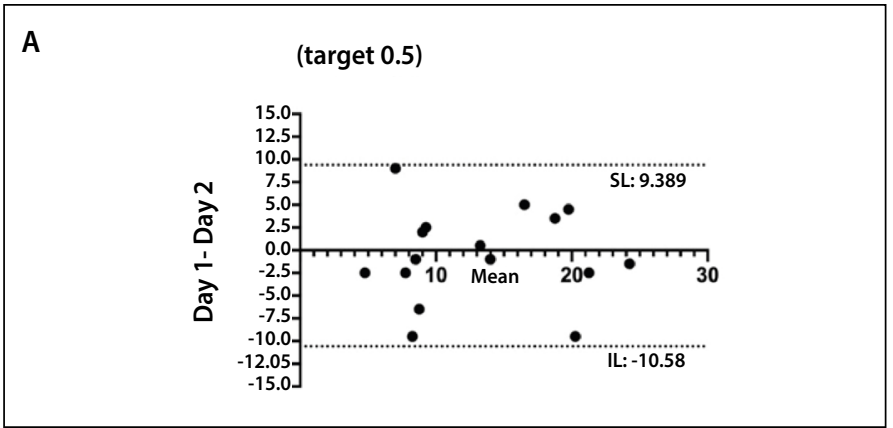

B

(target 1.0)

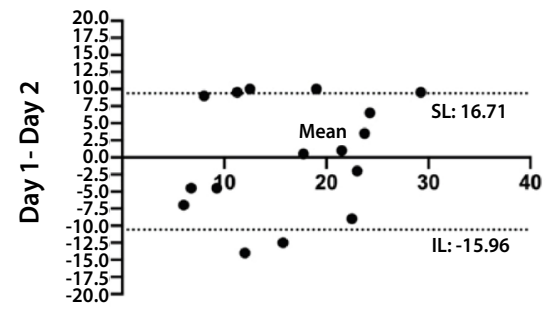

Figure 3. Bland-Altman graphical analysis of the data collection days for both developed targets.

Table 2. Selected test-retest reproducibility coefficients for the entire sample investigated.

\begin{tabular}{c|c|c|c|c|c|c}
\hline Targets & $\begin{array}{c}\text { Day 1 } \\
\text { (mean) }\end{array}$ & $\begin{array}{c}\text { Day 2 } \\
\text { (mean) }\end{array}$ & ICC & SEm & Bias & MDD \\
\hline 0.5 & 12.91 & 13.50 & 0.73 & 3.45 & -0.5938 & 8.00 \\
\hline 1.0 & 16.59 & 16.22 & 0.53 & 6.28 & 0.3750 & 14.56 \\
\hline
\end{tabular}

Key: ICC (intraclass correlation coefficient), SEm (standard error measurement), Bias (mean difference between days 1 and 2 of data collection), MDD (minimum detectable difference).

\section{DISCUSSION}

In this study, a recently developed protocol for assessing the precision of Paralympic boccia athletes was demonstrated. Because it was produced ecologically, ${ }_{17}^{7}$ in an attempt to consider and highlight the main technical characteristic of the game, to be easily produced using plastic sheeting, in addition to being able to be administered at the teams' own training sites, we consider this new resource (technological and methodological), with characteristics of logical validity, ${ }^{18}$ even though it has not been subjected to evaluation by trainers, athletes or other researchers in the Paralympic area.

The growing number of Paralympic boccia players in Brazil and the increasing demands on athletes, as an outcome of the results achieved in international events, have provided an opportunity to develop new sports assessment resources to ensure the quality of training sessions and make greater control of the effects of specific interventions and training loads during competitive periods possible. It should be noted that other Paralympic sports have already made progress with their performance evaluation methods. ${ }^{19-22}$

When we compared the two projected targets (RES-0.5 and RES-1.0), there were no significant differences in 3 of the 4 precision indicators (Figure 2, panels $A, B$ and $C$; maximum precision, short precision and medium precision, respectively). However, in long precision the result obtained from RES-1.0 was significantly greater than RES-0.5 (Figure 2, panel D). It is important to highlight that all Paralympic boccia athletes have severe motor impairment. This alone limits the production of strength and muscle resistance considerably, especially when exposed to greater energetic demands. ${ }^{14}$

Thus, because RES- 1.0 has a greater scoring area than RES-0.5, there is less possibility for accuracy on the part of the athlete, increasing the chances of achieving better precision results, thus causing greater negative influences of reduced motor control and fine movement adjustment. This same effect of the greater distance influencing the precision and motor adjustment of Paralympic boccia athletes has been reported in earlier studies, ${ }^{714}$ especially in athletes of classes BC2 and BC4 who have greater strength than the other functional classes ( $\mathrm{BC} 3$ and $\mathrm{BC} 1$ ).

This characteristic can be explained, at least in part, when we observe the mean values obtained for the other precision indicators evaluated (Figure 2). After the launch of the target ball, the athletes usually prefer to play the game in places close to their launch site (the boxes where the athletes are located). Thus the precision indicators achieved are expected to be higher up to midcourt, especially when evaluating athletes with more severe disabilities (cerebral palsy and muscular dystrophy). ${ }^{23-25}$

When comparing the data collection days, all the statistical coefficients evaluated were considered better for RES-0.5 than for RES-1.0. Observing the Bland-Altman graphical method (Figure 3), we found that the RES-0.5 data were all within the established confidence interval (95\%), as well as having lower limits of agreement in relation to RES-1.0 (RES-0.5: superior limit=-10.58 and inferior limit=9.389 versus RES-1.0: superior limit=16.71 and inferior limit=-15.96). This same effect of greater concordance was observed in the other indices evaluated (ICC and SEm, Table 2), showing less variation in the precision indicators in RES-0.5 compared to RES-1.0.

These results are reinforced by the lower values observed for MDD in RES-0.5 (Table 2). Thus, we recommend that, when using the targets for evaluation, you consider differences greater than 8.0 points for RES0.5 and 14.00 for RES-1.0 if you wish to realize significant improvements in the precision indices of your athletes from any throw distance being assessed. This information demonstrates greater sensitivity for measuring adaptation to the training routines for the RES-0.5 target, which was expected given the higher resolution of the points established. 
Although studies have been conducted to develop evaluation methods in Paralympic sports, 21,22,26 the methodological differences that exist in terms of assessment criteria, the design of scientific authenticity procedures, the different modalities and also the physical valences involved, limit comparisons with these investigations. Thus, it is necessary to develop further investigations with Paralympic athletes with severe motor disability in order to gain a better understanding of training and evaluation methods.

Other factors related to applicability need to be studied. The sample in the present study was composed mainly of athletes belonging to classes $\mathrm{BC} 2$ and $\mathrm{BC} 4(\mathrm{~N}=6)$. This indicates that this protocol tends to have better applicability to athletes with characteristics similar to those of our study participants and further studies with special focus on the other functional classes are needed. In addition, even though we included an athlete with only 3 months of experience in this study, we recommend that the protocol be applied, through previous familiarization, to players with higher levels of experience and playing time. It is worth noting that all the participants in our study had considerable familiarization time before the final collection of precision data.

Special attention should be paid to class BC3 because of the specific use of a ramp in addition to the participation of an assistant on the court. Although we recommend the "ramp break" in each execution of the protocol, this procedure may not be sufficient to enable the athlete to maintain their throwing position. It is important to note that information concerning class BC3 athletes is extremely scarce in the literature.
Although this investigation presents promising results around the use of the created protocol, it has several limitations that need to be highlighted. The small number of subjects reduces the ability to extrapolate from the evaluation parameter results obtained, especially when dealing with variables related to precision consistency. Additionally, the lack of a considerable number of athletes in all classes limits the possibility of creating specific criteria for each level of functionality of the athlete.

\section{CONCLUSIONS}

We conclude that the protocol produced is easy to apply, with a considerable level of logical validity in view of the specificity of the modality it is meant to assess. Additionally, it was found that both targets present moderate to excellent indicators of test-retest consistency. Preliminarily, we recommend using the lower-resolution target (RES-0.5) because of the lower values found in the indices that measure its reliability.

\section{ACKNOWLEDGEMENTS}

We thank the Coordenação de Aperfeiçoamento de Pessoal de Nível Superior (CAPES), and Fundação de Amparo à Pesquisa do Estado de Pernambuco (FACEPE), for the financial support to this research. We also thank the Associação Nacional de Desporto Para Deficientes (ANDE), Universidade Federal de Pernambuco (UFPE) and all athletes that ag reed to participate.

All authors declare no potential conflict of interest related to this article

AUTHORS' CONTRIBUTIONS: Each author made significant individual contributions to this manuscript. Oliveira SFM: contribution to the concept, study design, data analysis and interpretation, writing and critical review of its intellectual content, final approval of the version of the manuscript to be published; Oliveira LIGL: acquisition, analysis and interpretation of the study data; Oliveira JIV: acquisition, analysis and interpretation of the study data; Arruda SFA: acquisition, analysis and interpretation of the study data; Costa MC: contribution to the concept, study design, data analysis and interpretation.

\section{REFERENCES}

1. Wincler C, Mello MT. Esporte Paralimpico. São Paulo: Atheneu, 2012.

2. Dantas MJB, Dantas TLFS, Nogueira CD, Goria JI. Bocha paralímpica: história, iniciação e avaliação. Curitiba: Editora CRV, 2019.

3. Ovenden I, Dening T, Beer C. "Here everyone is the same" - A qualitative evaluation of participating in a Boccia (indoor bowling) group: Innovative practice. Dementia (London). 2019;18(2):785-92.

4. Willemink MJ, Es HW, Helmhout PH, Diederik AL, Kelder JC, Heesewijk JPM. The effects of dynamic isolated lumbar extensor training on lumbar multifidus functional cross-sectional area and functional status of patients with chronic non-specific low back pain. Spine (Phila Pa 1976). 2012;37(26):E1651-8.

5. Arroxellas RD, Romano RG, Cymrot R, Blascovi-Assis SM. Bocha adaptada: análise cinemática do arremesso e sua relação com a realidade virtual. Rev Bras Ciênc Esporte. 2017;39(2):160-7.

6. Morriss L, Wittmannova J. The effect of Blocked Versus Random Training Schedules on Boccia Skills Performance in Experienced Athletes With Cerebral Palsy. European Journal of Adapted Physical Activity. 2010;3(2): 17-28.

7. Leite I, Costa M, Banja T,Tashiro T, Oliveira S. Avaliação cinemática do arremesso tipo down arm de um jogador de bocha paradesportiva (Classe BC4) - um estudo de caso. ConScientiae Saúde. 2014;13(Supleme):80-4.

8. de Witte AMH, Hoozemans MJM, Berger MAM, Slikke RMA, Woude LHV, Veeger DEJ. Development, construct validity and test-retest reliability of a field-based wheelchair mobility performance test for wheelchair basketball. J Sports Sci. 2018;36(1):23-32.

9. Yilla AB, Sherrill C. Validating the Beck Battery of Quad Rugby Skill Tests. Adapted Physical Activity Quarterly. 1998;15:155-67.

10. Rietveld T, Vegter RJK, Slikke RMA, Hoekstra AE, Woude LHV, Groot S.. Wheelchair mobility performance of elite wheelchair tennis players during four field tests: Inter-trial reliability and construct validity. PLoS One. 2019;14(6):e0217514.

11. Oliveira S, Oliveira I, Severien R, Araújo E, Santos J, Milano R, et al. Desenvolvimento de testes para avaliação de velocidade e agilidade de jogadores de voleibol sentado. Revista Brasileira do Esporte Coletivo. 2017;1(2):30-6.

12. Roldan A, Sabido R, Barbado D, Caballero C, Reina R. Manual dexterity and intralimb coordination assessment to distinguish different levels of impairment in boccia players with cerebral palsy. Front Neurol. 2017;8:582.
13. Roldan A, Barbado D, Vera-Garcia FJ, Sarabia JM, Reina R. Inter-rater reliability, concurrent validity and sensitivity of current methods to assess trunk function in boccia player with cerebral palsy. Brain Sci. 2020;10(3):130.

14. Fong DTP, Yam KY, Chu VWS, Cheung RTH, Chan KM. Upper limb muscle fatigue during prolonged Boccia games with underarm throwing technique. Sports Biomech. 2012;11(4):441-51.

15. Bunce C. Correlation, Agreement, and Bland-Altman Analysis: Statistical Analysis of Method Comparison Studies. Am J Ophthalmol. 2009;148(1):4-6.

16. Davi SF, Arcuri JF, Labadessa IG, Pessoa BV, Costa JNF, Sentanin AC, et al. Reprodutibilidade do teste de caminhada e do degrau de 6 minutos em adultos jovens saudáveis. Rev Bras Med Esporte. 2014;20(3):214-8.

17. Thomas J, Nelson J, Silverman S. Métodos de pesquisa em atividade física. São Paulo: Artmed; 2002

18. Guedes DP. Manual prático para avaliação em educação física. São Paulo: Manole; 2005.

19. Vanlandewijck YC, Daly DJ, Theisen DM. Field test evaluation of aerobic, anaerobic, and wheelchair basketball skill performances. Int J Sports Med. 1999;20(8):548-54

20. Oliveira SFM, Bione AAG, Oliveira LIGL, Costa AV, Guimarães FJSP, Costa MC. The Compact Wheelchair Roller Dynamometer. Sports Med Int Open. 2017;1(4):E119-27.

21. Souto EC, Dos Santos Oliveira L, Neto AM, Greguol M. Autenticidade científica de um teste de agilidade para o voleibol sentado. Motricidade. 2015;11(4):82-91.

22. Oliveira L, Oliveira S, Guimarães F, Costa M. Contributions of body fat, fat free mass and arm muscle area in athletic performance of wheelchair basketball players. Motricidade. 2017;13(2):36-48.

23. Huang PC, Pan PJ, Ou YC, Yu YC, Tsai YS. Motion analysis of throwing Boccia balls in children with cerebral palsy. Res Dev Disabil. 2014;35(2):393-9.

24. Barak S, Mendoza-Laiz N, Gutiérrez Fuentes MT, Rubiera M, Hutzler Y. Psychosocial effects of competitive boccia program in persons with severe chronic disability. J Rehabil Res Dev. 2016;53(6):973-88

25. Tsai YS, Yu YC, Huang PC, Cheng HYK. Seat surface inclination may affect postural stability during Boccia ball throwing in children with cerebral palsy. Res Dev Disabil. 2014;35(12):3568-73.

26. Gorla JI, Costa e Silva AA, Costa LT, Campos LFCC. Validação da bateria Beck de testes de habilidades para atletas brasileiros de rugby em cadeira de rodas. Rev Bras Educ Fís Esporte (Impr). 2011;25(3):473-86. 